\title{
Aplicação de bactérias probióticas para profilaxia e tratamento de doenças gastrointestinais
}

\author{
Application of probiotic bacteria for prevention and \\ treatment of gastrointestinal diseases
}

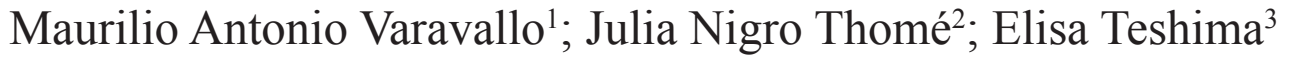

\section{Resumo}

\begin{abstract}
Bactérias probióticas como Bifidobactéria e Lactobacilos são importantes para a saúde humana, pois quando consumidas, podem aumentar o número e a atividade dos microrganismos intestinais com propriedades úteis ao hospedeiro. São muitas as doenças em que os probióticos tem efeitos benéficos, facilitando a formação da chamada barreira probiótica no intestino, impedindo, assim, a colonização da microbiota por bactérias patogênicas. Alguns dos mecanismos descritos para esse impedimento é a competição que ocorre no intestino favorecendo as bactérias probióticas, o estimulo do sistema imunológico facilitando a defesa do organismo, significativa redução dos níveis de colesterol total com diminuição do LDL colesterol, melhora da digestão de proteínas e aumento da absorção de vitaminas e minerais. Os alimentos que contém probióticos são chamados de Alimentos Funcionais, como, por exemplo, os leites fermentados que ajudam hoje pessoas com câncer de colo de intestino, doença de Cronh, diarréias causadas por vírus e bactérias, e diarréia do viajante. Porém, para que essas bactérias probióticas sejam realmente eficazes, é necessário que sejam resistentes ao suco gástrico e à bile, para que possam chegar até a microbiota e desempenhem suas funções. Esse trabalho salienta a importância das bactérias probióticas como Bifidobacteria e/ou Lactobacilos para a saúde humana.
\end{abstract}

Palavras-chave: Bactérias probióticas. Bifidobacterium. Lactobacillus. Doenças gastrointestinais.

\begin{abstract}
Probiotics bacteria such as Bifidobacterium ssp and Lactobacillus ssp are important for the health of human beings; therefore, whenever consumed, they increase the number and the activity of intestinal microorganisms with useful properties to the host, being essential for the production of symbiotic products. Probiotics has a positive effect on many diseases, facilitating to the formation of the probiotic barrier in the intestine, thus hindering the settling of microbiota for pathogenic bacteria. Some of the described mechanisms for this impediment are: competition in the intestine favoring the bacteria probiotics, stimulation of the Immunologic System thus facilitating the defense of the organism, reduction of cholesterol levels with reduction of the LDL cholesterol, improvement of the protein digestion and increase of vitamin absorption. Foods with probiotics are known as Probiotics Food, as for example, fermented milk which nowadays helps people with intestine cancer, Crohn's disease, diarrheas caused for virus and bacteria and traveler's diarrhea. However, for these probiotics bacteria to be really efficient, they must be resistant to the gastric juice and bile, so that they can reach the microbiota and perform their functions. This work had the purpose to point out the importance of probiotics bacteria such as Bifidobacterium and/or Lactobacillus for the health of human beings.
\end{abstract}

Keywords: Probiotics bacteria. Bifidobacterium. Lactobacillus. Gastrointestinal diseases.

${ }^{1}$ ITPAC - Instituto Tocantinense Presidente Antonio Carlos - Araguaína, TO. E-mail: varavallo@itpac.br

2 Departamento de Produtos Perigosos Infecciosos - DGM - Dangerous Goods Management, São Paulo, SP.

3 Departamento de Tecnologia, Universidade Estadual de Feira de Santana - Feira de Santa, BA. 


\section{Introdução}

Os probióticos são alimentos suplementados com microrganismos vivos (Lactobacillus e/ou Bifidobacterium) e que, consumidos regularmente em quantidades suficientes, devem produzir efeitos benéficos à saúde e ao bem estar; além dos efeitos nutricionais habituais que beneficiam o hospedeiro por meio da melhoria no equilíbrio da microbiota intestinal (FULLER, 1989; GIBSON; ROBERFROID, 1995; HENKER et al., 2007). Os probióticos fazem parte dos chamados Alimentos Funcionais, cujo principal alvo é a mucosa intestinal e a sua microbiota, estando inclusos neste grupo o iogurte, leites fermentados e alguns biscoitos (FULLER, 1989; BOOBIER; BAKER; DAVIES, 2006). Os possíveis mecanismos de ação dos probióticos incluem a síntese de substâncias microbianas contra as bactérias patogênicas, a competição por nutrientes necessários para o crescimento dos microrganismos patogênicos, a inibição da sua adesividade à mucosa intestinal, a modificação do $\mathrm{pH}$ do meio intestinal, o aumento da secreção da mucosa, a inativação das toxinas e seus receptores e a estimulação da fagocitose e das respostas imunológicas específicas ou inespecíficas contra os agentes patogênicos (FOX, 1988; MADSEN, 2001; MANNING; GIBSON, 2004; MATSUMOTO et al., 2005; PANT et al., 2007). O principal objetivo da utilização dos probióticos é aumentar o número e a atividade dos microrganismos intestinais com propriedades úteis ao hospedeiro (FULLER, 1989). Assim, as condições a que devem apresentar um bom probiótico são: a- apresentar resistência ao ácido do estômago, à bile e às enzimas pancreáticas e digestivas; $b$ - adesividade às células da mucosa intestinal; c- capacidade de colonização e velocidade específica de crescimento elevada; dprodução de substâncias antimicrobianas contra as bactérias patogênicas e; e- ausência de translocação (HAVENAAR; BRINK; HUIS-INT'VELD, 1992; SALMINEN; OUWEHAND; ISOLAURI，1998; OUWERHAND et al., 1999; SAARELA et al., 2000;
HOLZAPFEL; SCHILLINGER, 2002; DANIEL et al., 2006).

Os probióticos mais utilizados são estirpes de bactérias produtoras de ácido láctico como Lactobacillus e Bifidobacterium, que preenchem as condições para um bom probiótico (PANT et al., 2007). O fungo Saccharomyces boulardii é outro probiótico utilizado com freqüência (RODRIGUES et al., 1996; CZERUCKA et al., 2000; QAMAR et al., 2001; GEYIK et al., 2006; CANANI et al., 2007). Recentemente, um grupo de pesquisadores iniciaram estudos para a utilização de uma linhagem de Escherichia coli com características probióticas (KRUIS etal., 2004; SCHULTZ et al., 2004; UKENA et al., 2005; HENKER et al., 2007; SCHLEE et al., 2007; UKENA et al., 2007).

Os probióticos são utilizados na prevenção e tratamento de várias situações patológicas tais como:

a) Intolerância à lactose e a outros dissacarídeos - provavelmente é uma das utilizações mais antigas dos probióticos, pois desde há muito se sabe que o iogurte é muito melhor tolerado que o leite pelos indivíduos intolerantes à lactose. Esta melhor tolerância tem sido atribuída à redução do conteúdo em lactose no iogurte devido à fermentação pelas bactérias produtoras de ácido láctico, à atividade da $\beta$-galactosidase das próprias bactérias que produzem o iogurte e, também, à menor velocidade de esvaziamento gástrico deste em relação ao leite. A administração de um probiótico como Sacharomyces boulardii melhora a sintomatologia em indivíduos com défict em sacarase-isomaltase. Espécies de Bifidobacterium e Lactobacillus têm sido frequentemente utilizadas na produção de iogurtes e outros produtos do leite fermentado (KOLARS, et al., 1984; SAVAIANO et al., 1984; FULLER, 1991; MARTINI et al., 1991; MONTES et al., 1995; JIANG; MUSTAPHA; SAVAIANO, 1996; ROLFE, 2000; GORBACH, 2000; MARTEAU et al., 2001; CALLANAN; 
BERESFORD; ROSS, 2005; JANER et al., 2005; WARD et al., 2006).

b) Diarréia aguda infecciosa - O maior número de estudos com probióticos tem incidido quer na prevenção quer no tratamento da diarréia aguda infecciosa (ISOLAURI, 2003; CANANI et al., 2007). Em ensaios preventivos, verificou-se uma diminuição significativa da incidência da diarréia nas crianças que ingeriram probióticos em comparação com os controles (ROLFE, 2000; GORBACH, 2000; SHAMIR et al., 2005). Em ensaios terapêuticos, o conjunto dos resultados aponta para diferenças significativas a favor dos grupos com probióticos no que diz respeito à intensidade e duração da diarréia, ao número de dias de internamento e dos dias em que os vírus são eliminados no caso da diarréia e rotavírus (ROLFE, 2000; JUNTUNEN, et al., 2001; PANT et al., 2007). Tendo em conta que a diarréia é uma causa importante de mortalidade nos países em desenvolvimento, sobretudo em crianças e adultos com má nutrição, os probióticos, pela sua eficácia preventiva e terapêutica, são úteis em Saúde Pública (ROLFE, 2000; JUNTUNEN et al., 2001).

c) Diarréia X probióticos - este benefício está associado à produção de substâncias antimicrobianas que inibem o crescimento de bactérias patógenas (PROTIC et al., 2005).

d) Diarréia associada a antibióticos - várias estirpes têm comprovado a eficácia dos probióticos na prevenção e tratamento da diarréia associada aos antibióticos. Os mais utilizados têm sido Bifidobactéria, Saccharomyces boulardi e Lactobacilos (HICKSON et al., 2007).

e) Diarréia do viajante - a diarréia do viajante é a doença mais comum durante a visita às regiões tropicais e sub-tropicais. O efeito dos probióticos para prevenir esta diarréia não está suficientemente demonstrado e alguns trabalhos são contraditórios. No entanto, alguns ensaios clínicos demonstram um declínio de incidência da diarréia de acordo com as regiões visitadas e as doses utilizadas (SZAJEWSKA; MRUKAWICZ, 2005).

f) Doença inflamatória crônica do intestino e outras situações gastroenterológicas - parece bastante promissor o uso de probióticos, especialmente de Saccharomyces boulardii e do Lactobacillus casei na doença de Crohn, na colite ulcerosa e na inflamação crônica da bolsa ileal (KARIMI; PENA; VAN BODEGRAVEN, 2005; MATSUMOTO et al., 2005; SCANLAN et al., 2006). Existem resultados animadores com a utilização de probioticos na síndrome do intestino curto e na alergia alimentar, provavelmente pela diminuição da permeabilidade intestinal e pelas suas propriedades antiinflamatórias (ISOLAURI; KIRJAVAINEN; SALMINEN, 2002; ISOLAURI; OUWRHAND; LAITINEN, 2005; MATSUMOTO et al., 2005; DANIEL et al., 2006).

g) Dislipidemias - uma das propriedades das bifidobactérias é a sua influência no metabolismo lipídico. Vários estudos clínicos apresentam como resultado de utilização dos probióticos, diminuições significativas dos níveis de colesterol total pela diminuição do colesterol LDL, enquanto os níveis de colesterol HDL aumentam ligeiramente. $\mathrm{O}$ efeito hipocolesterolemiante das bifidobactérias resulta da diminuição da absorção e do transporte do colesterol alimentar para o fígado via quilomicrons e, por outro lado, pela desconjunção dos sais biliares com menor absorção do colesterol pelo intestino. A niacina formada pelas bifidobactérias diminui o fluxo de ácidos graxos livres que, ao diminuir a biossíntese da lipoproteína VLDL, contribui para a redução dos níveis plasmáticos dos triglicérides (PEREIRA; McCARTNEY; GIBSON, 2003; CHIU et al., 2005; LIONG; SHAH, 2005a; ZHAO; YAHG, 2005).

h) Outras situações clínicas - Embora com resultados ainda mal definidos, os probióticos 
estão para ser utilizados na fibrose cística, nas infecções urogenitais e nas vaginites tendo em conta a sua ação imunoestimulante, inibição da atividade enzimática bacteriana e recolonização do trato vaginal (RESTA-LENERT; BARRETT, 2003; SARTOR, 2005; MATTO et al., 2005; PELUSO et al., 2007; ZÁRATE; SANTOS; NADER-MACIAS, 2007).

O iogurte, um dos mais antigos alimentos funcionais consumidos pelos humanos, apresenta algumas propriedades nutricionais de alto valor, que são as seguintes:

a) Conter baixo teor de lactose: a lactose é parcialmente transformada em acido láctico durante o processo da fermentação, o que facilita a assimilação do iogurte em indivíduos com intolerância à lactose e que, por isso, têm problemas em assimilar os nutrientes do leite, especialmente cálcio (SAVAIANO et al., 1984; BOGDANOVA; BOGDANOVA, 1991; TAMINE; MARSHALL; ROBINSON, 1995; KNUT, 2001).

b) Proteólise e digestão: as proteínas do leite, que têm um alto valor biológico, são parcialmente pré-digeridas por ação de enzimas proteolíticas das bactérias lácticas, o que permite uma melhor digestão (MARTINI et al., 1991; TAMINE; MARSHALL; ROBINSON, 1995; KNUT, 2001; JANER et al., 2005).

c) Vitaminas: as vitaminas do leite ajudam o crescimento das bactérias lácticas que, por sua vez, produzem outras vitaminas, aumentando assim a variedade de vitaminas presentes no iogurte (BOGDANOVA; BOGDANOVA, 1991; TAMINE; MARSHALL; ROBINSON, 1995; KNUT, 2001).

d) Minerais: o iogurte apresenta uma ampla variedade de minerais provenientes do leite, destacando-se com maior importância o cálcio, que neste produto apresenta-se com elevada biodisponibilidade (BOGDANOVA;
BOGDANOVA, 1991; TAMINE; MARSHALL; ROBINSON, 1995; KNUT, 2001).

\section{Probióticos e mecanismos de ação}

Os primeiros estudos científicos sobre probióticos começam com o trabalho de Metchnikoff, do Instituto Pasteur. Esse investigador postulou que os probióticos produziam efeitos benéficos no hospedeiro, porque antagonizavam as bactérias perniciosas no intestino (FULLER, 1989).

A hipótese inicial sobre os probióticos propunha que as cepas bacterianas que aderissem à superfície da mucosa intestinal de forma mais eficiente seriam mais benéficas para os seus portadores (ROLFE, 2000).

O termo probiótico foi definido inicialmente como: "organismos vivos que quando ingeridos exercem efeito benéfico no balanço da microbiota bacteriana intestinal do hospedeiro" e ampliado posteriormente para: "organismos vivos que quando ingeridos em determinado número exercem efeitos benéficos para a saúde" (BRADY; GALLAHER; BUSTA, 2000). A definição atual é a seguinte: "suplemento alimentar microbiano vivo, que afeta de forma benéfica seu receptor, por meio da melhoria do balanço microbiano intestinal" (ROLFE, 2000; REID; HAMMOND, 2005).

Várias ações benéficas são atribuídas ao uso dos Probióticos, principalmente Bifidobactéria e Lactobacilos como, por exemplo, aumentam de maneira significativa o valor nutritivo e terapêutico dos alimentos, pois ocorre um aumento dos níveis de vitaminas do complexo B e aminoácidos. Absorção acrescida de cálcio, ferro e magnésio (ROLFE, 2000; COUDRAY et al., 2005; SNELLING, 2005), sendo:

a) Fortalecemosistemaimunológico,peloincremento no número de células protetoras (MATSUMOTO et al., 2005; PELUSO et al., 2007); 
b) Possuem efeito funcional benéfico no organismo, equilibram a microbiota intestinal, e atuam no controle do colesterol pela produção de propionato que inibe a síntese de colesterol hepático (TESHIMA, 2003);

c) Possuem uma particular importância para os indivíduos com intolerância à lactose, devido ao aumento de uma enzima que facilita a digestão da lactose (BARILLAS; SOLOMONS, 1987; MONTES et al., 1995; TESHIMA, 2003).

Além das propriedades mencionadas, os probióticos devem ter algumas características particulares, como manterem-se viáveis ao longo do tempo da vida de prateleira do produto alimentício, não transportarem genes transmissores de resistência a antibióticos e possuirem propriedades anti-mutagênicas e anticarcinogênicas, assim como resistirem a fagos e ao oxigênio (ROLFE, 2000; SALMINEN; NURMI; GUEIMONDE， 2005; SNELLING, 2005; NICOLAS et al., 2007).

Os probióticos normalmente têm pouco tempo de vida e ação e, por isso mesmo, devem ser mantidos bem refrigerados. Ao serem ingeridos através dos alimentos, vão para o intestino e ali se somam à microbiota já existente, sem se fixarem, equilibrando-a e, com isso, auxiliam o trabalho de absorção dos nutrientes. Os principais mecanismos de ação dos probióticos serão descritos a seguir:

\section{Mecanismos de ação}

Competição por sítios de ligação

As bactérias probióticas ocupam os sítios de ligações (receptores ou pontos de ligação) na mucosa intestinal, formando um tipo de barreira física às bactérias patogênicas. Assim, as bactérias patogênicas não conseguem se ligar a esses receptores e consequentemente são excluídas pela competição (FULLER, 1991; HAVENAAR; BRINK; HUIS-INT 'VELD, 1992; OUWERHAND et al., 1999; CROSS, 2002; LAVERMICOCCA et al., 2005; REID; HAMMOND, 2005).
Competição por nutrientes

A escassez de nutrientes disponíveis na luz intestinal que possam ser metabolizados pelas bactérias patogênicas é um fator limitante de manutenção das mesmas neste ambiente, uma vez que o intestino já se encontra colonizado por microrganismos probióticos, que naturalmente competem por alimentos com as bactérias patogênicas por alimentos. As bactérias probióticas se nutrem de ingredientes que foram parcialmente degradados pelas enzimas digestivas normais, ou que foram intencionalmente adicionados à dieta como prebióticos (GIBSON; ROBERFROID, 1995; ROLFE, 2000; GIBSON; MCCARTNEY; RALTALL, 2005).

Estímulo do sistema imune

Alguns gêneros de bactérias intestinais, como o Lactobacillus e o Bifidobacterium estão diretamente relacionados com o estímulo da resposta imune por aumento da produção de anticorpos, ativação de macrófagos, proliferação de células $\mathrm{T}$ e produção de interferon, entre outros. Entretanto, o verdadeiro mecanismo pelos quais essas bactérias estimulam o sistema imune ainda permanece com muitos pontos a serem esclarecidos (FULLER, 1991; ISOLAURI, et al., 2001; MATSUMOTO et al., 2005; RINNE et al., 2005; PELUSO et al., 2007).

Produção de substâncias antibacterianas

As bactérias da microbiota intestinal e/ou componentes dos probióticos podem produzir e liberar compostos como as bacteriocinas (VILLANI et al., 1995; RODRIGUEZ, 1996; NAIDU; BIDLACK; CLEMENS, 1999; VÉLEZ et al., 2007), ácidos orgânicos e peróxidos de hidrogênio (HAVENAAR; BRINK; HUIS-INT'VELD, 1992; NAIDU; BIDLACK; CLEMENS, 1999), que têm ação bacteriostática ou bactericida, especialmente em relação às bactérias patogênicas. As bacteriocinas são substâncias antibióticas de ação local, que 
inibem o crescimento de patógenos intestinais. As bactérias ácido lácticas produzem nisina, diplococcina, lactocidina, bulgaricina e reuterina. Essas substâncias apresentam atividade inibitória, tanto para bactérias gram-negativas quanto para gram-postitivas (KEERSMAECKER et al., 2006; CLEUSIX et al., 2007; CORR et al., 2007; LIMA et al., 2007).

As bactérias intestinais, utilizando-se de ingredientes alimentares não absorvidos integralmente pelo hospedeiro, produzem alguns ácidos orgânicos, como o propiônico, o acético, o butírico e o láctico, além do peróxido de hidrogênio, cujos espectros de ação incluem também a inibição do crescimento de bactérias patogênicas. Aparentemente, a ação bacteriostática dos ácido graxos de cadeia curta é dependente do $\mathrm{pH}$, pois quanto maior a redução deste, maior a quantidade de ácido e efeito antibacteriano mais intenso. Não deve ser descartada a idéia de que todas estas substâncias antibacterianas podem atuar em associação, não só entre si como fatores desencadeantes e processantes, mas também como bloqueio físico (VILLANI et al., 1995; RODRIGUES et al., 1996; NAIDU; BIDLACK; CLEMENS, 1999; NAABER et al., 2004; KURDI et al., 2006; LAUGHTON et al., 2006).

Os Probióticos se nutrem de ingredientes que não foram total ou parcialmente degradados pelas enzimas digestivas normais ou foram intencionalmente adicionados à dieta. Estas substâncias, intencionalmente adicionadas com a finalidade de "alimentar" as bactérias probióticas, são conhecidas como Prebióticos e serão motivo de discussão mais pormenorizada, adiante (GIBSON; ROBERFROID, 1995; GIBSON; MCCARTNEY; RALTALL, 2005).

Além disso, outras ações benéficas podem ser atribuídas ao uso de probióticos, como: auxílio na digestão e absorção de nutrientes (envolvimento na bioquímica intestinal, especialmente em relação à ação sobre os sais biliares); produção de nutrientes para células da mucosa intestinal; redução da produção de amoníaco e auxílio na eliminação de aminas biogênicas tóxicas; produção de vitaminas do grupo B; melhoria na absorção e biodisponibilidade de minerais como cálcio e ferro; proteção dos vilos e das superfícies absorventes contra toxinas irritantes produzidas pelos microrganismos patogênicos, permitindo assim, a regeneração da mucosa intestinal lesada e restauração da microbiota intestinal após antibioticoterapia (SHAH, 1993; LORIKOPP, 2001; LIONG; SHAH, 2005; DANIEL et al., 2006; UKENA et al., 2007).

\section{O que são prebióticos?}

O termo Prebiótico foi empregado por Gibson e Roberfroid em 1995 para designar "ingredientes nutricionais não digeríveis que afetam beneficamente o hospedeiro e estimulam seletivamente o crescimento e atividade de uma ou mais bactérias benéficas do cólon, melhorando a saúde do seu hospedeiro".

A principal ação dos prebióticos é estimular o crescimento e/ou ativar o metabolismo de algum grupo de bactérias benéficas do trato intestinal. Dessa maneira, os prebióticos agem intimamente relacionadosaosprobióticos;constituindoo"alimento" das bactérias probióticas (SCHREZENMEIR; DE VRESE, 2001; MANDERSON et al., 2005; BOUHNIK et al., 2006).

O uso de produtos denominados Prebióticos em associação como os Probióticos apresentam ações benéficas superiores aos antibióticos promotores de crescimento, notadamente. Por serem produtos essencialmente naturais, não determinam resíduos nos produtos de origem animal e não induzem ao desenvolvimento de resistência às drogas. As características gerais dos Prebióticos são: a- não ser metabolizados ou absorvidos durante a sua passagem pelo trato digestivo superior; $b$ - servir como substrato a uma ou mais bactérias intestinais benéficas (estas serão estimuladas a crescer e/ou 
tornarem-se metabolicamente ativas); c- possuir a capacidade de alterar a microbiota intestinal de maneira favorável à saúde do hospedeiro; d- induzir efeitos benéficos sistêmicos na luz intestinal do hospedeiro (GIBSON; ROBERFROID, 1995; LANGLANDS et al., 2004; BENGMARK; MARTINDALE, 2005; LIONG; SHAH, 2005b; OSMAN et al., 2006; SAULNIER et al., 2007).

\section{Substâncias prebióticas}

Alguns açúcares absorvíveis ou não, fibras, álcoois de açúcares e oligossacarídeos estão dentro deste conceito de prebióticos. Desses, os oligossacarídeos - cadeias curtas de polissacarídeos compostos de três a 10 açúcares simples ligados entre si - tem recebido mais atenção pelas inúmeras propriedades prebióticas atribuídas a eles (GIBSON; McCARTNEY; RASTALL, 2005; LIONG; SHAH, 2005a, 2005b; AMARETTI et al., 2007).

Os frutooligossacarídeos são polissacarídeos que têm demonstrado excelentes efeitos prebióticos, "alimentando" seletivamente algumas espécies de Lactobacilos e Bifidobactérias (principalmente) e, desta maneira reduzindo a quantidade de outras bactérias como Bacteróides, Clostridium e coliformes (BENGMARK; MARTINDALE, 2005; MEULEN et al., 2006).

Os Prebióticos podem ser obtidos na forma natural em sementes e raízes de alguns vegetais como a chicória, cebola, alho, alcachofra, aspargo, cevada, centeio, grãos de soja, grão-de-bico e tremoço. Também, podem ser extraídos por cozimento ou através de ação enzimática ou alcoólica. Há também os oligossacarídeos sintéticos, obtidos através da polimerização direta de alguns dissacarídeos da parede celular de leveduras ou fermentação de polissacarídeos. Os oligossacarídeos sintéticos têm apresentado melhores resultados como Prebiótico e menos efeitos colaterais (GRAJEK; OLEJNIK; SIP, 2005; MANDERSON et al., 2005; SHOAF et al., 2006; SAULNIER et al., 2007).

\section{Como agem os prebióticos?}

As substâncias prebióticas agem alimentando e estimulando o crescimento de diversas bactérias intestinais benéficas, cujos metabólitos atuam diminuindo o $\mathrm{pH}$ mediante o aumento da quantidade de ácidos orgânicos presentes no ceco. Por outro lado, atuam bloqueando os sítios de aderência (principalmente a D-manose), imobilizando e reduzindo a capacidade de fixação de algumas bactérias patogênicas na mucosa intestinal. Especula-se que os oligossacarídeos possam atuar, também, estimulando o sistema imune, mediante a diminuição indireta da translocação intestinal por patógenos, que determinariam infecções após atingir a corrente sangüínea (NICOLE; VIEIRA, 2000; LIONG; SHAH, 2005a, 2005b; MAKRAS; ACKER; VUYST, 2005; SHOAF et al., 2006; HAFER et al., 2007).

As principais contribuições dos prebióticos são a diminuição do risco de osteoporose, diminuição do risco da obesidade e Diabetes tipo II, e diminuição da freqüência do câncer do cólon (SUGAWARA et al., 2006).

O isolamento das bactérias bífidas de lactentes tem importância e utilização na produção de produtos simbióticos (contém microrganismos probióticos e substâncias prebióticas) e que poderão ser empregados como adjunto dietético primeiramente em instituições hospitalares, para compor a dieta de convalescentes, com a finalidade de recompor sua microbiota intestinal e de protegê-la do efeito deletério inevitável do consumo de antibióticos, prevenindo o estabelecimento de diarréias e atenuando inflamações intestinais (FRIEDMAN, 2005; FALONY et al., 2006; OSMAN et al., 2006). As bactérias bífidas diferem de acordo com a espécie, em suas características de crescimento e resposta ao frutooligossacarídeo (MEULEN et al., 2006; AMARETTI et al., 2007) 


\section{Alimento probiótico - leite fermentado}

A origem dos leites fermentados data de longo tempo, não sendo possível uma precisa definição de seu aparecimento. No início do século XX, a partir de estudos de Metchnikoff, no Institute Pasteur (Paris - França), as pesquisas começaram a associar a produção dos leites fermentados com o metabolismo de microrganismos lácteos. A partir destas descobertas, várias culturas láticas foram isoladas e caracterizadas, bem como o processo de fermentação passou a ser controlado e padronizado pelas indústrias.

Por iogurte, entende-se o produto cuja fermentação se realiza com cultivos protosimbióticos de Lactobacillus delbrueckii subsp. bulgaricus, aos quaispodem-seacompanhar, deformacomplementar, outras bactérias ácido-lácticas que, por sua atividade, contribuem para a determinação das características do produto final e leite fermentado ou cultivado o produto cuja fermentação se realiza com um ou vários dos seguintes cultivos: Lactobacillus acidophilus, Lactobacillus casei, Bifidobacterium $s p$ e/ou outras bactérias ácido-lácticas que, por sua atividade, contribuem para a determinação das características do produto final (BARTRAM et al., 1994; ADHIKARI et al., 2000; WARD et al., 2006).

Cerca de 56 espécies do gênero Lactobacillus foram descritas até hoje. Essas bactérias estão distribuídas por vários nichos ecológicos, sendo encontradas por todo o trato gastrointestinal e geniturinário, constituindo uma importante parte da microbiota de homens e animais.A sua distribuição, porém, é afetada por diversos fatores ambientais como: $\mathrm{pH}$, disponibilidade de oxigênio, nível de substrato especifico, presença de secreções e interações bacterianas. Raramente são relacionados com casos de infecções gastrointestinais e cepas empregadas tecnologicamente são microrganismos seguros e não patogênicos. Além disto, os lactobacilos possuem propriedades potencialmente probióticas, favorecendo beneficamente o organismo humano. Por isto, L. acidophilus e L. casei têm sido amplamente utilizados pelos laticínios para produção de leites fermentados e outros derivados lácteos (SOZZI; SMILEY, 1980; PEDROSA et al., 1995; MUSTAPHA; JIANG; SAVAIANO, 1997; GUERIN-DANAN et al., 1998; GOMES; MALCATA, 1999).

A viabilidade de $L$. acidophilus pode ser melhorada nos produtos pela seleção adequada de cepas resistentes a acidez estomacal e a bile, utilização de recipientes impermeáveis ao oxigênio, fermentação em duas etapas, adaptação ao estresse, incorporação de peptídeos e aminoácidos (GOMES; MALCATA, 1999).

Atualmente existem várias possibilidades de utilização terapêutica de Lactobacilos e Bifidobactérias, as quais podem ser citadas: areposição de microbiota intestinal desejável após longa exposição à uma anitibioticoterapia. Essas bactérias auxiliam a digestão e o tratamento de doenças imunossupressoras. Isso acontece, provavelmente, porque o Lactobacillus estimula a produção de citocinas por macrófagos (SCHIFFRIN et al., 1995; DJOUZI et al., 1997; DONNETHUGHES et al., 1999; PEREZ et al., 2007); batuação contra Helicobacter pylori no tratamento de úlceras gástricas em humanos (MICHETTI et al., 1999; WANG et al., 2004; SHEU et al., 2006); c- redução dos níveis plasmáticos de colesterol e da ocorrência de doenças cardíacas coronarianas (PEREIRA; McCARTNEY; GIBSON, 2003; LIONG; SHAH, 2005a); d- biodegradação de substâncias carcinogênicas no intestino (WOLLOWSKI et al., 1999; FEMIA et al., 2002); e- tratamento de câncer de intestino (REDDY; RIVERSON, 1993; WOLLOWSKI et al., 1999); fredução da ocorrência de infecções do trato urinário inferior (cistite, vaginite) (HILTON et al., 1992; REID; ZALAI; GARDINER, 2001; TOMÁS et al., 2003; VITALI et al., 2007); g- aumento da absorção de lactose em pessoas intolerantes (SAVAIANO et al., 1984; MARTINI et al., 1991; MUSTAPHA et al., 1997; JANER et al., 2005); h- tratamento 
de diarréias e infecções intestinais (RANI; KHETARPAUL, 1998; ISOLAURI, 2003); i- efeito de imunomodulação em pessoas com deficiência do sistema imunológico (DONNET-HUGHES et al., 1999; MEYDANI; HA, 2000; SHEIL et al., 2006; PEREZ et al., 2007).

Existe também a associação de L. acidophilus e Saccharomyces lactis na produção de leite acidófilo com leveduras, apresentando importantes propriedades terapêuticas, pois esta levedura produz substâncias que atuam contra Mycobacterium tuberculosis. Esse produto tem consistência viscosa e sabor levemente ácido, apresentando atividade antibiótica máxima com três dias de fabricação (BOGDANOVA; BOGDANOVA, 1991).

A adição de bactérias probióticas aos produtos lácteos exige uma série de cuidados. Uma das principais dificuldades encontradas está relacionada a palatabilidade, ou seja, com o sabor devido a propriedade de fermentação dessas bactérias. Esses produtos lácteos são produzidos com uma base igual aos produtos não probióticos, para que não haja descaracterização e se assegure sua funcionalidade. Alguns pontos devem ser seguidos para a produção dos alimentos próbioticos como: a- adequação da cultura levando em conta o público alvo, como crianças, idosos e adultos; bcrescimento e sobrevivência em leite; c- produção de ácido na quantidade desejada e na taxa esperada; d- ausência de alteração do sabor característico do produto; e- a cultura deve ser resistente as mudanças bruscas de $\mathrm{pH}$ quando ingeridas e a acidez do produto deve resistir a presença da bile; f- apresentar a concentração mínima de $10^{6}$ UFC/g para Lactobacilos ssp e $10^{7} \mathrm{UFC} / \mathrm{g}$ para Bifidobacterium ssp (MARSHALL; COLE, 1983; ADHIKARI et al., 2000; ELLI et al., 2006).

\section{Principais doenças gastrointestinais}

O trato gastrointestinal humano e a microbiota intestinal estão envolvidos em uma série de doenças. Especialmente o intestino grosso, é o principal local de multiplicação de bactérias, vírus e parasitas nocivos, os quais podem trazer doenças para o organismo. Os principais microrganismos patogênicos que podem estar presentes em alimentos incluem Campylobacter, salmonellae, listeriae e certas linhagens de Escherichia coli (FRIEDMAN, 2005).

O resultado de um super crescimento dessas bactérias no intestino pode ser uma diarréia aguda. Há, contudo, outras formas mais crônicas de doenças intestinais e muito mais graves, tais como a doença inflamatória do intestino (exemplo, colite ulcerativa e doença de Crohn), câncer de cólon e colite pseudomembranosa. Cada uma dessas desordens pode ter origem num determinado tipo de bactéria (FRIEDMAN, 2005; KARIMI; PENA; VAN BODEGRAVEN, 2005; MATSUMOTO et al., 2005; DANIEL et al., 2006; OSMAN et al., 2006; HENKER et al., 2007).

Estima-se que cerca de 400 espécies de bactérias, separadas em duas categorias, habitem o trato gastrointestinal humano: a- aquelas consideradas benéficas, probióticas, como, por exemplo, as Bifidobactérias e Lactobacilos e b- aquelas consideradas prejudiciais, nocivas, como, por exemplo, as Enterobacteriaceae e Clostridium ssp (FRIEDMAN, 2005).

O epitélio intestinal intacto com sua microbiota intestinal funciona como uma barreira ao movimento de bactérias patogênicas, antígenos e outras substâncias nocivas ao intestino. Em pessoas saudáveis, essa barreira é estável, protegendo e facilitando as funções intestinais normais. Entretanto, quando a microbiota intestinal ou as células epiteliais são perturbadas por antígenos alimentares, patógenos, substâncias químicas ou radiação, defeitos nos mecanismos de proteção da barreira podem ocorrer. A microbiota intestinal alterada pode levar à diarréia, inflamação da mucosa, desordem de permeabilidade ou ativação de carcinógenos no conteúdo intestinal. É aí que 
entram os alimentos probióticos, cuja função é equilibrar a microbiota bacteriana do intestino, promovendo saúde para as pessoas ao diminuir os riscos de doenças intestinais (DENDUKURI et al., 2005; MATTO et al., 2005; OSMAN et al., 2006).

As bactérias probióticas empregadas hoje, principalmente em leites fermentados e em alguns iogurtes, atuam no balanço da microbiota intestinal e nas disfunções do trato intestinal. Inúmeros benefícios têm sido relatados (CHEN; WALKER, 2005) e incluem: a- prevenção e melhora de diarréia (SALMINEN; OUWEHAND; ISOLAURI, 1998; ISOLAURI, 2003; HENKER et al., 2007; PANT et al., 2007); b- restabelecimento da integridade da mucosa intestinal (GUARNER; MALAGELADA, 2003); c- prevenção e controle de câncer de cólon (SAWAMURA; YAMAGUCHI; TOGE, 1994); d- melhora no sistema imunológico (maior resistência às infecções) (PERDIGON et al., 1999; MATSUMOTO et al., 2005; SHEIL et al., 2006); e- melhora de constipação (SARTOR, 2005); fmelhora da alergia a certos alimentos, incluindo intolerância à lactose do leite (SHAH, 1993); gdiminuição do colesterol (LIONG; SHAH, 2005a; ZHAO; YANG, 2005); h- melhor absorção de cálcio (COUDRAY et al., 2005; VINDEROLA; MATAR; PERDIGÓN, 2007); i- auxílio contra infecções no trato urinário em mulheres (HILTON; RINDOS; ISENBERG, 1995; ZÁRATE; SANTOS; NADERMACIAS, 2007).

O intestino é um ecossistema complexo formado por três componentes principais que estão em permanente trocas entre si: a barreira mucosa; o sistema imunológico local (GALT - tecido linfóide associado ao intestino) e a microbiota (MATARESE, 2003).

A microbiota intestinal desenvolve-se em etapas durante a vida do hospedeiro, sob a influência dos alimentos, do estado clínico e das condições ambientais. A microbiota encontrada no intestino adulto permanece surpreendentemente estável no decorrerdotempo(MATARESE,2003).Amicrobiota de um humano adulto consiste em uma biomassa de mais de 100 trilhões de bactérias com mais de 400 espécies diferentes que estão sempre em intensa atividade, principalmente no cólon, possuindo papel fisiológico importante no hospedeiro. A população dominante compreende as bactérias estritamente anaeróbias: Bacteroides, Bifidobacterium, Eubacterium e Peptostreptococcus. Essas quatro espécies são encontradas em concentrações entre $10^{8}$ e $10^{11} \mathrm{UFC} / \mathrm{g}$ de conteúdo intestinal em todos os seres humanos. Dentre as diferentes espécies de bactérias, as que produzem ácido láctico são sempre pesquisadas em razão dos efeitos fisiológicos que exercem na saúde dos seres humanos e animais, cada uma apresentando uma variedade de benefícios (BOURLIOUX et al., 2003). As bactérias produtoras de ácido láctico, morfologicamente, são divididas em cocos e bacilos. São classificadas de acordo com as condições de crescimento e também de acordo com o tipo de fermentação do ácido láctico. Distribuídas na natureza em grande quantidade, nem todas sobrevivem no intestino humano. Para atingir e sobreviver no intestino devem ser resistentes ao ácido gástrico, ao suco biliar e, além disso, ter afinidade com o tubo gastrointestinal (FULLER, 1991; TERMONT et al., 2006).

A bactéria Lactobacillus casei cepa Shirota, isolada pelo médico Minoru Shirota em 1930 no Japão, deu origem ao primeiro alimento probiótico utilizado na produção de leites fermentados e bebidas lácteas ácidas. Em estudo de Yuki et al. (1999), observou-se que após ingestão de Lactobacillus casei shirota ocorreu recuperação de $10^{7}$ bactérias por grama nas fezes, indicando que sobrevivem e se multiplicam no tubo gastrintestinal após ingestão de leite fermentado. Para o intestino manter suas funções ótimas, o equilíbrio entre as bactérias da microbiota deve ser mantido, porém alguns fatores exercem efeitos nocivos contra a microbiota probiótica, gerando uma sobrecarga no sistema imunológico e a conseqüente quebra da homeostase intestinal. Ocorrendo o desequilíbrio na microbiota intestinal, as bactérias patogênicas, exógenas e 
endógenas podem se desenvolver, contribuindo para o surgimento de infecções. Algumas bactérias podem produzir efeito nocivo à saúde do hospedeiro como resultado de várias formas de atividades enzimáticas. A atividade beta-glucuronidase deste tipo de microbiota pode aumentar, e disso resulta a liberação de substâncias potencialmente carcinogênicas. Isso também é válido para algumas enzimas envolvidas no metabolismo do nitrogênio, que podem resultar na degradação do triptofano, indol, nitratos e aminas secundárias, para derivativos com potencial carcinogênico (MARTEAU; SEKSIK; JIAN, 2002). Os probióticos e o uso de leites fermentados levaram ao desenvolvimento mais lento de câncer induzido e podem combater o crescimento de células cancerígenas no intestino, bexiga e estômago, apresentando efeitos antitumorais. Esses efeitos são atribuídos à inibição da atividade mutagênica provocada pela diminuição de enzimas implicadas na geração de substâncias carcinogênicas e/ou mutagênicas (BRADY; GALLAHER; BUSTA, 2000). A mortalidade por câncer de cólon está em segundo lugar, após o câncer de pulmão em homens, e o de mama nas mulheres. A dieta é um fator importante que influencia o risco do câncer de cólon, com relação em mais de $75 \%$ dos casos (RAFTER, 2003).

Quatro mecanismos foram sugeridos como responsáveis pelos efeitos antitumorais dos lactobacilos, especialmente os L. casei Shirota; a- inibição da atividade das enzimas relacionadas a carcinogênese e produzidas pelas bactérias intestinais; b- ligação de pirolisatos mutagênicos potentes aos corpos celulares; c- supressão urinária da atividade mutagênica derivada dos alimentos; d- imunomodulação. Os três primeiros mecanismos envolvem diminuição de atividade mutagênica e ofertam maior impacto em órgãos relacionados ao processo digestório, como a bexiga, o cólon e o reto (YUKI et al., 1999).

A terapia simbiótica também tem demonstrado eficácia na prevenção e tratamento de colite (OSMAN et al., 2006). O efeito antitumoral do $L$. casei Shirota, após a administração parenteral, pode ser determinado por meio do aumento da imunidade não-específica e também específica a tumores do hospedeiro, pela produção de citocinas após ativação de macrófagos e linfócitos T e pela estimulação das células Natural Killer. O efeito antitumoral do $L$. casei Shirota após a administração oral também pode ser determinado por efeito imunopotencializador (BRADY; GALLAHER;BUSTA, 2000). Sawamura, Yamaguchi e Toge (1994) determinaram a atividade Natural Killer e a resposta a fitohemaglutinina em linfócitos obtidos do sangue periférico e linfonodos regionais, antes e depois da ressecção do tumor em pacientes com câncer de cólon, tratados com uma preparação contendo L. casei Shirota (na proporção de $10^{10}$ células/g) por 10 dias consecutivos até a véspera da cirurgia. Um outro grupo de pacientes permaneceu sem tratamento como grupo-controle. $\mathrm{O}$ tratamento mostrou que não houve alteração significativa na atividade Natural Killer e na resposta a fitohemaglutinina. Entretanto, a análise citométrica do fluxo dos subconjuntos de linfócitos apresentou um aumento de células $T$ Helper e células Natural Killer, e diminuição de células T supressoras no sangue periférico dos pacientes que receberam a preparação. Prova-se, assim, que a ingestão desses lactobacilos, assim como alimentos simbióticos podem ser benéficos ao tratamento de pacientes com câncer de cólon.

\section{Diarréias}

A Diarréia consiste na eliminação anormal de fezes, líquidas ou moles, em grande quantidade e frequentemente acompanham aumento dos movimentos intestinais (hiperistaltismo). Normalmente, os alimentos e os líquidos seguem um caminho desde o estômago até ao intestino delgado, local onde os nutrientes e a água são absorvidos, e seguem então para o intestino grosso onde os restos não digeridos, podem ser armazenados e mais tarde, eliminados (PROTIC et al., 2005). Algumas vezes, infecções, intoxicações, inflamações ou outras 
situações podem impedir o funcionamento normal do intestino delgado ou do grosso. O movimento intestinal, que normalmente é lento e em ondas, pode aumentar, conduzindo os alimentos e líquidos rapidamente através dos intestinos. A conseqüência deste rápido movimento é o aparecimento de fezes aquosas, ou seja, a diarréia. Os principais problemas das diarréias são as perdas de água e eletrólitos (sais minerais) que ela ocasiona, trazendo o risco de desidratação, principalmente em crianças (PROTIC et al., 2005; HENKER et al., 2007). O termo diarréia também é conhecido por: gastroenterite aguda, toxinfecção alimentar; dor de barriga, desarranjo e soltura (PROTIC et al., 2005).

Algumas causas de diarréia podem ser listadas: a- infecciosa (microrganismos como: vírus, salmonela, vibrião da cólera, shiguela, giárdia / ameba); b- intoxicação alimentar - ingestão de alimento contaminado com toxinas produzidas por plantas ou microrganismos, além de substâncias químicas como praguicidas, aditivos alimentares, antibióticos e hormônios; c- uso de alguns tipos específicos de medicamentos (efeitos colaterais): antibióticos podem causar diarréia após um mês de sua ingestão; d- uso de laxativos como leite de magnésio, cáscara, fenolftaleína; e- sensibilidade a algum tipo específico de alimento, por exemplo intolerância à lactose; f- erro alimentar - como pelo uso de leite integral ou de outros tipos de alimentos na dieta do bebê, no período em que ele deveria estar em aleitamento materno exclusivo; g- doença dos intestinos - como colites ulcerativas, doença de Crohn, presença de divertículos e câncer de cólon (BORRUEL et al., 2002; PROTIC et al., 2005; HENKER et al., 2007).

Quando a causa é infecciosa, a transmissão ocorre principalmente: pela ingestão de água contaminada pelas fezes de doentes; de alimentos contaminados pela água, pelas mãos contaminadas de doentes ou por utensílios contaminados; por fezes de pessoas, que embora não doentes (isto é, sem diarréia), sejam portadoras de algum microrganismo e, por meio de objetos contaminados (garfos, colheres, copos, mamadeiras, chupetas ou brinquedos) que são levados à boca.

A infecção pelo rotavírus pode se apresentar como um quadro leve, com diarréia líquida e duração limitada, podendo chegar a quadros graves com desidratação, febre e vômitos. Em alguns casos, pode não apresentar sintomas (JUNTUNEN et al., 2001). O rotavírus é eliminado em alta quantidade nas fezes de crianças infectadas, sendo transmitido pela via fecal-oral, por água ou alimentos, por contato pessoa-a-pessoa, objetos contaminados e, provavelmente, também por secreções respiratórias. Essa doença possui uma alta capacidade de dispersão (ROLFE, 2000). O rotavírus vem sendo considerado, em todo o mundo, o principal responsável por diarréia em crianças menores de cinco anos e tem sido a principal causa de surtos de diarréia em hospitais, e em creches ou pré-escolas (JUNTUNEN et al., 2001; PANT et al., 2007). Sabe-se que a doença por rotavírus é de distribuição universal, embora com diferentes características de comportamento da doença, dependendo da área, se de clima temperado ou tropical. Nas áreas de clima temperado, manifestam-se mais nos meses frios e nas regiões tropicais, de forma peculiar a determinada população ou região, por casos esporádicos ou surtos, em qualquer estação do ano (ROLFE, 2000; JUNTUNEN et al., 2001).

\section{Diarréias agudas}

O termo diarréia aguda refere-se ao início súbito e à duração menor que três semanas, e a maioria resolve-se entre de três a cinco dias. A maior parte das diarréias agudas é causada por vírus, bactérias ou parasitas. Há microrganismos produtores de toxinas que alteram o funcionamento intestinal. Mais que estes, as toxinas diminuem a absorção de líquidos pelo intestino ou estimulam sua perda para a luz intestinal (JUNTUNEN et al., 2001; CANANI et al., 2007). Alguns microrganismos invadem a mucosa, causando lesões com secreção de sangue, muco e pus, o que caracteriza a 
disenteria, um tipo particular de diarréia. Além dos microrganismos, certas substâncias alteram a absorção e/ou a secreção intestinal, como vários laxantes ou efeitos adversos de medicamentos, que se traduzem por diarréia (JUNTUNEN et al., 2001). O uso de diversos antibióticos pode levar à alteração da microbiota intestinal, um distúrbio ecológico que permite o desenvolvimento de alguns microrganismos agressivos ao meio, que podem resultar em diarréias, sendo grave a conhecida por "Colite Pseudomembranosa", nome dado devido a placas branquicentas que cobrem variadas áreas da mucosa do intestino grosso (DIELEMAN et al., 2003; HUMEN et al., 2005; HICKSON et al., 2007).

Diarréia do viajante

A causa é a conhecida E. coli. Ocorre mais onde os fatores sanitários não são adequados. Esta infecção pode ser prevenida, evitando-se a ingestão de alimentos dito frescos não cozidos e frutas (RESTA-LENERT; BARRET, 2003.) Frutas como a laranja, que tem uma proteção natural são seguras. Particularmente, a lavagem com água de torneira e uso de gelo, devem ser evitadas. Bebidas engarrafadas (água mineral, refrigerante) são as recomendadas (RESTA-LENERT; BARRET, 2003).

\section{Diarréia crônica}

Há certas doenças que podem causar diarréia crônica. Estas incluem: colites ulcerativas, doença de Crohn, diverticuloses e câncer de cólon. Todas são doenças que requerem cuidados e tratamento médico. O cólon irritável ocorre quando o intestino não se contrai de maneira rítmica: se exagerada pode provocar diarréia, se vagarosa resulta em intestino preso. É freqüente ocorrer alternância de intestino preso e diarréia. $\mathrm{O}$ estresse emocional freqüentemente agrava esses sintomas (ROLFE, 2000; JUNTUNEN et al., 2001; RESTA-LENERT; BARRET, 2003).

\section{Doenças inflamatórias intestinais}

Compreendem a retocolite ulcerativa e a doença de Crohn e são caracterizadas por evacuações sanguinolentas com muco, com períodos de melhora e exacerbação espontâneas. Os fatores mais relevantes na perpetuação do processo inflamatório são a herança genética, a contaminação ambiental, a mudança de hábitos alimentares e, mais recentemente, a alteração da microbiota intestinal. Apesar dos extensos estudos, os mecanismos que desencadeiam a seqüência dos eventos inflamatórios ainda não foram totalmente esclarecidos (KARIMI; PENA; VAN BODEGRAVEN, 2005; MATSUMOTO et al., 2005; DANIEL et al., 2006; SCANLAN et al., 2006).

Algumas pesquisas concluem que os portadores dessas doenças têm perda de tolerância e uma resposta imunológica agressiva a uma microbiota alterada (BORRUEL et al., 2000; NOBAEK et al., 2000) Outros estudos mostram que as doenças inflamatórias intestinais são patologias que podem apresentar melhor resposta com o uso de probióticos (KRUIS et al., 2004; MIMURA et al., 2004; DANIEL et al., 2006; OSMAN et al., 2006; SHEIL et al., 2006).

Muitos probióticos são estáveis somente por períodos limitados, quando armazenados em geladeiras. Os principais veículos são os iogurtes, leites fermentados e fórmulas lácteas infantis. Os que são comercializados em cápsulas ou em pó são mais estáveis e podem ser armazenados em prateleiras e diluídos em líquidos. Quando os probióticos são expostos ao calor ou oxigênio pode ocorrer destruição das bactérias. Novas técnicas de microencapsulação estão sendo desenvolvidas para preservar a sobrevivência dos microrganismos ao atravessar o estômago e duodeno e os benefícios são promissores (HELLER, 2001; BENGMARK; MARTINDALE, 2005). 


\section{Doenças alérgicas}

A utilização de probióticos, especialmente Lactobacillus e Bifidobacterium, também é citada no tratamento das doenças alérgicas (ISOLAURI; OUWERHAND; LAITINEN, 2005), baseada nos mecanismos de barreira da mucosa intestinal e no desequilíbrio de Th1 e Th2 a vários antígenos (VAARALA, 2003). As citocinas dos linfócitos Th2 (IL-4, IL-5, IL-10 e IL-13) predominam nas respostas alérgicas e são responsáveis pela produção de anticorpos IgE e ativação de eosinófilos (HEYMAN; MENARD, 2002). Os Lactobacillus inibem a produção das citocinas Th2 e, dessa forma, controlam a resposta alérgica.

\section{Conclusão}

Muitos estudos científicos são continuamente desenvolvidos para averiguar os efeitos benéficos dos probióticos nas várias condições que afetam o bem estar do hospedeiro. A microbiota gastrointestinal pode ser alterada por vários fatores interdependentes que podem afetar esse ambiente, no qual a correta concentração e combinação das espécies ali presentes é mantida, prejudicando o equilíbrio que se busca. Existem várias espécies de bactérias probióticas em uso atualmente, inclusive comercial, que proporcionam a melhoria e o bem estar do hospedeiro. Na última década, foi crescente o trabalho com biotecnologia de bactérias probióticas, a técnica de manipulação de genes vem tomando lugar dos trabalhos de isolamento, embora estes devam sempre continuar, devido a variabilidade genética existente no ambiente. A curto ou médio prazo muito mais alimentos funcionais poderão estar disponíveis ao consumidor, com linhagens que desempenham funções específicas. Isso será possível com o incremento e otimização dos trabalhos até agora concluídos, por proporcionarem grande conhecimento acerca dos efeitos benéficos dos probióticos.

\section{Referências}

ADHIKARI, K.; MUSTAPHA, A.; GRUN, U. I.; FERNANDO, L. Viability of microencapsulated Bifidobacteria in set yogurt during refrigerated Storage. Journal of Dairy Science, Champaign, v. 83, n. 9, p. 1946-1951, 2000.

AMARETTI, A.; BERNARDI, T.; TAMBURINI, E.; ZANONI, S.; LOMMA, M.; MATTEUZZI, D.; ROSSI, M. Kinetics and metabolism of Bifidobacterium adolescentis MB 239 growing on glucose, galactose, lactose, and galactooligosaccharides. Applied and Environmental Microbiology, Washington, v. 73, n. 11, p. 3637-3644, 2007.

BARILLAS, C.; SOLOMONS, N. W. Effective reduction of lactose maldigestion in preschool children by direct addition of beta-galactosidases to milk at mealtime. Pediatrics, Evanston, v. 79, n. 5, p. 766-772, 1987.

BARTRAM, H.; SCHEPPACH, W.; GERLACH, S.; RUCKDESCHEL, G.; KELBER, E.; KASPER, H. Does yogurt enriched with Bifidobacterium longum affect colonic microbiology and fecal metabolites in healthy subjects? American Journal of Clinical Nutrition, Bethesda, v. 59, p. 428-432, 1994.

BENGMARK, S.; MARTINDALE, R. Probiotics and antioxidants as functional foods. Acta Biochimica Polonica, Warszawa, v. 52, n. 3, p. 665-671, 2005.

BOGDANOVA, E. A.; BOGDANOVA, G. I. Fermented products manufacturing. In: ROBINSON, R. K. Therapeutic properties of fermented milks. New York: Elsevier, 1991. p. 23.-24.

BOOBIER, W. J.; BAKER, J. S.; DAVIES, B. Development of a healthy biscuit: an alternative approach to biscuit manufacture. Nutrition Journal, London, v. 5, n. 7, p. 1-7, 2006

BORRUEL, N.;CAROL, M.; CASELLAS, F.;ANTOLIN, M.; DE LARA, F.; ESPIN, E.; NAVAL, J.; GUARNER, F.; MALAGELADA, J. R. Increased mucosal tumors necrosis factor alpha production in Crohn's disease can be down regulated ex vivo by probiotic bacteria. Gut, London, v. 51, n. 5, p. 659-664. 2002.

BOUHNIK, Y.; RASKINE, L.; SIMONEAU, G.; PAINEAU, D.; FRANCIS BORNET, F. The capacity of short-chain fructo-oligosaccharides to stimulate faecal bifidobacteria: a dose-response relationship study in healthy humans. Nutrition Journal, London, v. 5, n. 8, p. 1-6, 2006.

BOURLIOUX, P.; KOLETZKO, B.; GUARNER, F.; BRAESCO, $\mathrm{V}$. The intestine and its microflora are partners for the protection of the host: report on the 
Danone Symposium "The Intelligent Intestine", held in Paris, June 14, 2002. American Journal of Clinical Nutrition, Bethesda, v. 78, n. 4, p. 675-683, 2003.

BRADY, L. J.; GALLAHER, D. D.; BUSTA, F. F. The role of probiotic cultures in the prevention of colon cancer. Journal of Nutrition, Bethesda, v. 130, n. 2S, p. 410S-414S, 2000.

CALlANAN, M. J.; BERESFORD, T. P.; ROSS, R. P. Genetic diversity in the lactose operons of Lactobacillus helveticus strains and its relationship to the role of these strains as commercial starter cultures. Applied and Environmental Microbiology, Washington, v. 71, n. 3, p. 1655-1658, 2005.

CANANI, R. B.; CIRILLO, P.; TERRIN, G.; CESARANO, L.; SPAGNUOLO, M. I.; VINCENZO, A.; ALBANO, F.; PASSARIELLO, A.; MARCO, G.; MANGUSO, F.; GUARINO, A. Probiotics for treatment of acute diarrhoea in children: randomised clinical trial of five different preparations. British Medical Journal, London, v. 335, n. 7614, p. 340, 2007.

CHEN, C. C.; WALKER, W. A. Probiotics and prebiotics: role in clinical disease states. Advances in Pediatrics, Chicago, v. 52, p. 77-113, 2005.

CHIU, C. H.; LU, T. Y.; TSENG, Y. Y.; PAN, T. M. The effects of Lactobacillus fermented milk on lipid metabolism in hamsters fed on high cholesterol diet. Applied Microbiology and Biotechnology, Berlin, v. 71, n. 2, p. 238-245, 2005.

CLEUSIX, V.; LACROIX, C.; VOLLENWEIDER, S.; DUBOUX, M.; BLAY, G. L. Inhibitory activity spectrum of reuterin produced by Lactobacillus reuteri against intestinal bacteria. Microbiology, Reading, v. 7, n. 101, p. 1-9, 2007.

CORR, S. C.; LI, Y.; RIEDEL, C. U.; O’TOOLE, P. W.; HILL, C.; GAHAN, C. G. M. Bacteriocin production as a mechanism for the antiinfective activity of Lactobacillus salivarius UCC118. Proceedings of the National Academy of Sciences USA, Melville, v. 104, n. 18, p. 7617-7621, 2007.

COUDRAY, C.; RAMBEAU, M.; FEILLET-COUDRAY, C.; TRESSOL, J. C.; DEMIGNE, C.; GUEUX, E.; MAZUR, A.; RAYSSIGUIER, Y. Dietary inulin intake and age can significantly affect intestinal absorption of calcium and magnesium in rats: a stable isotope approach. Nutrition Journal, London, v. 4, n. 29, p. 117-122, 2005.

CROSS, M. L. Microbes versus microbes: immune signals generated by probiotic lactobacilli and their role in protection against microbial pathogens. FEMS Immunology and Medical Microbiology, Amsterdam, v. 34, n. 4, p. 245-253, 2002.
CZERUCKA, D.; DAHAN, S.; MOGRABI, B.; ROSSI, B.; RAMPAL, P. Saccharomyces boulardii preserves the barrier function and modulates the signal transduction pathway induced in enteropathogenic Escherichia coliinfected T84 cells. Infection and Immunity, Washington, v. 68 , n. 10, p. 5998-6004, 2000.

DANIEL, C.; POIRET, S.; GOUDERCOURT, D.; DENNIN, V.; LEYER, G.; POT, B. Selecting lactic acid bacteria for their safety and functionality by use of a mouse colitis model. Applied and Environmental Microbiology, Washington, v. 72, n. 9, p. 5799-5805, 2006.

DENDUKURI, N.; COSTA, V.; MCGREGOR, M.; BROPHY, J. M. Probiotic therapy for the prevention and treatment of Clostridium difficile-associated diarrhea: a systematic review. Canadian Medical Association Journal, Ottawa, v. 173, n. 2, p. 167-170, 2005.

DIELEMAN, L.; GOERRES, M.; ARENDS, A.; SPRENGERS, D.; TORRICE, C.; HOENTJEN, F.; GRENTHER, W.; SARTOR, R. B. Lactobacillus GG prevents recurrent of colitis in HLA-B27 transgenic rats after antibiotic treatment. International Journal of Gastroenterology and Hepatology, London, v. 52, n. 3, p. 370-376, 2003.

DJOUZI, Z.; ANDRIEUX, C.; DEGIVRY, M.; BOULEY, C.; SZYLIT, O. The association of yogurt starters with Lactobacillus casei DN 114.001 in fermented milk alters the composition and matebolism of intestinal microflora in germ-free rats and human flora-associated rats. Journal of Nutrition, Bethesda, v. 127, n. 11, p. 22602266, 1997.

DONNET-HUGHES, A.; ROCHAT, F.; SERRANT, P.; AESCHLIMANN, J. M.; SCHIFFRIN, E. J. Modulation of nonspecific mechanisms of defense by lactic acid bacteria: effective dose. Journal of Dairy Science, Champaign, v. 82, n. 5, p. 863-869, 1999.

ELLI, M.; CALLEGARI, M. L.; FERRARI, S.; BESSI, E.; CATTIVELLI, D.; SOLDI, S.; MORELLI, L.; FEUILLERAT, N. G.; ANTOINE, J. Survival of yogurt bacteria in the human gut. Applied and Environmental Microbiology, Washington, v. 72, n. 7, p. 5113-5117, 2006.

FALONY, G.; VLACHOU, A.; VERBRUGGHE, K.; VUYST, L. D. Cross-feeding between Bifidobacterium longum bb536 and acetate-converting, butyrate-producing colon bactéria during growth on oligofructose. Applied And Environmental Microbiology, Washington, v. 72, n. 12, p. 7835-7841, 2006.

FEMIA, A. P.; LUCERI, C.; DOLARA, P.; GIANNINI, A.; BIGGERI, A.; SALVADORI, M.; CLUNE, Y.; 
COLlins, K. J.; PAGLIERANI, M.; CADERNI, G. Antitumorigenic activity of the prebiotic inulin enriched with oligofructose in combination with the probiotics Lactobacillus rhamnosus and Bifidobacterium lactis on azoxymethane-induced colon carcinogenesis in rats. Carcinogenesis, New York, v. 23, n. 11, p. 1953-1960, 2002.

FOX, S. M. Probiotics: intestinal inoculants for production animals. Veterinary Medicine, Lenexa, v. 83, n. 8 , p. 806-830, 1988.

FRIEDMAN, G. Probiotic, prebiotic and comensal bacteria perspectives and clinical application in gastroenterology. Gastroenterology Clinics of North America, Philadelphia, v. 34, n. 3, p. 12-16, 2005.

FULLER, R. Probiotics in human medicine. Gut, London, v. 32, n. 4, p. 439-442, 1991.

Probiotics in man and animals. Journal of Applied Bacteriology, Oxford, v. 66, n. 5, p. 365-378, 1989.

GEYIK, M. F.; ALDEMIR, M.; HOSOGLU, S.; AYAZ, C.; SATILMIS, S.; BUYUKBAYRAM, H.; KOKOGLU, O. F. The effects of Saccharomyces boulardii on bacterial translocation in rats with obstructive jaundice. Annals of the Royal College of Surgeons of England, London, v. 88, n. 2, p. 178-180, 2006.

GIBSON, G. R.; MCCARTNEY, A. L.; RASTALL, R. A. Prebiotics and resistance to gastrointestinal infections. British Journal of Nutrition, London, v. 93, n. 1, p. 31-34, 2005.

GIBSON, G. R.; ROBERFROID, M. B. Dietary modulation of the human colonic microbiota: introducing the concept of Probiotic. Journal of Nutrition, Bethesda, v. 125 , n. 6 , p. 1401-1412, 1995.

GOMES, P. M. A.; MALCATA, X. F. Agentes probióticos em alimentos, aspectos fisiológicos e terapêuticos e aplicação tecnológica. Boletim de Biotecnologia, Lisboa, n. 64, p. 12-22, dez. 1999.

GORBACH, S. L. Probiotics and gastrointestinal health. American Journal of Gastroenterology, New York, v. 95, n. 1 , p. $52-54,2000$.

GRAJEK, W.; OLEJNIK, A.; SIP, A. Probiotics, prebiotics and antioxidants as functional foods. Acta Biochimica Polonica, Warszawa, v. 52, n. 3, p. 665-671, 2005.

GUARNER, F.; MALAGELADA, J. R. Gut flora in health and disease. Lancet, London, v. 361, n. 9356, p. 512-519, 2003.

GUERIN-DANAN, C.; CHABANET, C.; PEDONE, C.; POPOT, F.; VAISSADE, P.; BOULEY, C.; SZYLIT, O.; ANDRIEUX, C. Milk fermented with yogurt cultures and Lactobacillus casi compared with yogurt and gelled milk: influence on intestinal microflora in healthy infants. American Journal of Clinical Nutrition, Bethesda, v. 67, n. 1, p. 111-117, 1998.

HAFER, A.; KRÄMER, S.; DUNCKER, S.; KRÜGER, M.; MANNS, M. P.; BISCHOFF, S. C. Effect of oral lactulose on clinical and immunohistochemical parameters in patients with inflammatory bowel disease: a pilot study. BioMed Central Gastroenterology, London, v. 7, n. 36, p. 1-11, 2007.

HAVENAAR, R.; BRINK, B. T.; HUIS-INT'VELD, J. H. J. Selection of strains for probiotic use. London: Chapman e Hall, 1992.

HELLER, J. K. Probiotic bacteria in ferment foods: product characteristics and starter organisms. American Journal of Clinical Nutrition, Bethesda, v. 73, n. 2, p. 374-379, 2001.

HENKER, J.; LAASS, M.; BLOKHIN, B. M.; BOLBOT, Y. K.; MAYDANNIK, V. G.; ELZE, M.; WOLFF, C.; SCHULZE, J. The probiotic Escherichia coli strain Nissle $1917(\mathrm{EcN})$ stops acute diarrhoea in infants and toddlers. European Journal of Pediatrics, Berlin, v. 166, n. 4, p. 311-318, 2007.

HEYMAN, M.; MENARD, S. Probiotic microorganisms: how they affect intestinal pathophysiology. Cellular and Molecular Life Science, Basel, v. 59, n. 7, p. 1151-1165, 2002.

HICKSON, M.; D’SOUZA, A. L.; MUTHU, N.; ROGERS, T. R.; WANT, S.; RAJKUMAR, C.; BULPITT, C. J. Use of probiotic Lactobacillus preparation to prevent diarrhoea associated with antibiotics: randomised double blind placebo controlled trial. British Medical Journal, London, v. 335, n. 7610, p. 1-5, 2007.

HILTON, E.; ISENBERG, H. D.; ALPERSTEIN, P.; FRANCE, K.; BORENSTEIN, M. T. Ingestion of yogurt containing Lactobacillus acidophilus as prophylaxis for candidal vaginitis. Annals of Internal Medicine, Philadelphia, v. 116, n. 5, p. 353-357, 1992.

HILTON, E.; RINDOS, R.; ISENBERG, H. D. Lactobacillus GG vaginal suppositories and vaginitis. Journal of Clinical Microbiology, Washington, v. 33, n. 5, p. 1433-1439, 1995.

HOLZAPFEL, W. H.; SCHILLINGER, U. Introduction to pre and probiotics. Food Research International, Amsterdam, v. 35, n. 2, p. 109-116, 2002.

HUMEN, M. A.; ANTONI, G. L.; BENYACOUB, J.; COSTAS, M. E.; CARDOZO, M. I.; KOZUBSKY, L.; SAUDAN, K.; BOENZLI-BRUAND, A.; BLUM, S.; SCHIFFRIN, E. J.; PÉREZ, P. F. Lactobacillus johnsonii Lal antagonizes Giardia intestinalis in vivo. Infection 
and Immunity, Washington, v. 73, n. 2, p. 1265-1269, 2005.

ISOLAURI, E. Probiotics for infectious diarrhoea. Gut, London, v. 52, n. 3, p. 436-437, 2003.

ISOLAURI, E.; KIRJAVAINEN, P. V.; SALMINEN, S. Probiotics: a role in the treatment of intestinal infection and inflammation. Gut, London, v. 50, n. 3, p. 54-59, 2002.

ISOLAURI, E.; OUWERHAND, A. C.; LAITINEN, K. Novel approaches to the nutritional management of allergic infant. Acta Paediatrica, Stockholm, v. 94, n. 4, p. 110-114, 2005.

ISOLAURI, E.; SÜTAS, Y.; KANKAANPÄÄ, P.; ARVILOMMI, H.; SALMINEN, S. Probiotics: effects on immunity. American Journal of Clinical Nutrition, Bethesda, v. 73, n. 4, p. 44-50, 2001.

JANER, C.; ARIGONI, F.; LEE, B. H.; PELÁEZ, C.; REQUENA, T. Enzymatic ability of Bifidobacterium animalis subsp. lactis to hydrolyze milk proteins: identification and characterization of endopeptidase $\mathrm{O}$. Applied and Environmental Microbiology, Washington, v. 71, n. 12, p. 8460-8465, 2005.

JIANG, T.; MUSTAPHA, A.; SAVAIANO, D. A. Improvement of lactose digestion in humans by ingestion of unfermented milk containing Bifidobacterium longum. Journal of Dairy Science, Champaign, v. 79, n. 5, p. 750757, 1996.

JUNTUNEN, M.; KIRJAVAINEN, P.; OUWEHAND, A. C.; SALMINEN, S.; ISOLAURI, E. Adherence of probiotic bacteria to human intestinal mucus in healthy infants and during rotavirus infection. Clinical and Diagnostic Laboratory Immunology, Washington, v. 8, n. 2, p. 293-296, 2001.

KARIMI, O.; PENA, A. S.; VAN BODEGRAVEN, A. A. Probiotics in arthralgia in patients with ulcerative colitis and Crohn's disease: a pilot study. Drugs of Today, Barcelona, v. 41, n. 7, p. 453-459, 2005.

KEERSMAECKER, S. C. J.; BRAEKEN, K.; VERHOEVEN, T. L. A.; VÉLEZ, M. P.; LEBEER, S.; VANDERLEYDEN, J.; HOLS, P. Flow cytometric testing of green fluorescent protein-tagged Lactobacillus rhamnosus GG for response to defensins. Applied and Environmental Microbiology, Washington, v. 72, n. 7, p. 4923-4930, 2006.

KNUT, J. H. Probiotic bacteria in fermented foods: product characteristics and starter organisms. American Journal of Clinical Nutrition, Bethesda, v. 73, n. 2, p. 374-379, 2001.
KOLARS, J. C.; LEVITT, M. D.; AOUJ, M.; SAVAIANO, D. A. Yogurt auto digesting source of lactose. New England Journal of Medicine, Boston, v. 310, n. 1, p. 1-3, 1984.

KRUIS, W.; FRIC, P.; POKROTNIEKS, J.; LUKAS, M.; FIXA, B.; KASCAK, M.; KAMM, M. A.; WEISMUELLER, J.; BEGLINGER, C.; STOLTE, M.; WOLFF, C.; SCHULZE, J. Maintaining remission of ulcerative colitis with the probiotic Escherichia coli Nissle 1917 is as effective as with standard mesalazine. Gut, London, v. 53, n. 11, p. 1617-1623, 2004.

KURDI, P.; KAWANISHI, K.; MIZUTANI, K.; YOKOTA, A. Mechanism of Growth Inhibition by Free Bile Acids in Lactobacilli and Bifidobacteria. Journal of Bacteriology, Washington, v. 188, n. 5, p. 1979-1986, 2006.

LANGLANDS, S. J.; HOPKINS, M. J.; COLEMAN, N.; CUMMINGS, J. H. Prebiotic carbohydrates modify the mucosa associated microflora of the human large bowel. Gut, London, v. 53, n. 11, p. 610-1616, 2004.

LAUGHTON, J. M.; DEVILLARD, E.; HEINRICHS, D. E.; REID, G.; MCCORMICK, J. K. Inhibition of expression of a staphylococcal superantigen-like protein by a soluble factor from Lactobacillus reuteri. Microbiology, Reading, v. 152, n. 4, p. 1155-1167, 2006.

LAVERMICOCCA, P.; VALERIO, F.; LONIGRO, S. L.; ANGELIS, M.; MORELLI, M.; CALLEGARI, M. L.; RIZZELLO, C. G.; VISCONTI, A. Study of adhesion and survival of lactobacilli and bifidobacteria on table olives with the aim of formulating a new probiotic food. Applied and Environmental Microbiology, Washington, v. 71, n. 8, p. 4233-4240, 2005.

LIMA, E. T.; ANDREATTI FILHO, R. L.; OKAMOTO, A. S.; NOUJAIM, J. C.; BARROS, M. R.; CROCCI, A. J. Evaluation in vitro of the antagonistic substances produced by Lactobacillus spp. isolated from chickens. Canadian Journal of Veterinary Research, Ottawa, v. 71, n. 2, p. 103-107, 2007.

LIONG, M. T.; SHAH, N. P. Optimization of cholesterol removal by probiotics in the presence of prebiotics by using a response surface method. Applied and Environmental Microbiology, Washington, v. 71, n. 4, p. 1745-1753, 2005a.

. Production of organic acids from fermentation of mannitol, fructooligosaccharide and inulin by cholesterol removing Lactobacillus acidophilus shain. Journal of Applied Microbiology, Oxford, v. 99, n. 4, p. 783-793, 2005 b. 
LORIKOPP, H. Prophylactic and therapeutic use of probiotics. Journal of the American Dietetic Association, Chicago, v. 101, n. 2, p. 229-238, 2001.

MADSEN, K. L. The use of probiotics in a gastrointestinal disease. Canadian Journal of Gastroenterology, Kingston, v. 15, n. 12, p. 817-822, 2001.

MAKRAS,L.;ACKER, G.V.;VUYST,L.D.Lactobacillus paracasei subsp. paracasei 8700:2 degrades inulin-type fructans exhibiting different degrees of polymerization. Applied and Environmental Microbiology, Washington, v. 71, n. 11, p. 6531-6537, 2005.

MANDERSON, K.; PINART, M.; TUOHY, K. M.; GRACE, W. E.; HOTCHKISS, A. T.; WIDMER, W.; YADHAV, M.P.; GIBSON, G. R.; RASTALL, R.A. In vitro determination of prebiotic properties of oligosaccharides derived from an orange juice manufacturing by-product stream. Applied and Environmental Microbiology, Washington, v. 71, n. 12, p. 8383-8389, 2005.

MANNING,T. S.; GIBSON, G. R. Microbial gut interaction in health and disease, prebiotics, best practice and research. Journal of Clinical Gastroenterology, New York, v. 18, n. 2, p. 287-298, 2004.

MARSHALL, V. M.; COLE, W. M. Threonine aldolase and alcohol dehydrogenase activities in Lactobacillus bulgaricus and Lactobacillus acidophilus and their contribution to flavor production in fermented milks. Journal of Dairy Research, Champaign, v. 50, n. 4, p. 375-379, 1983.

MARTEAU, P. R.; VRESE, M.; CELLIER, C. J.; SCHREZENMEIR, J. Protection from gastrointestinal diseases with the use of probiotics. American Journal of Clinical Nutrition, Bethesda, v. 73S, n. 2, p. 430S-436S, 2001.

MARTEAU, P.; SEKSIK, P.; JIAN, R. Probiotics and intestinal health effects: a clinical perspective. British Journal of Nutrition, London, v. 88, n. 1, p. 51-57, 2002.

MARTINI, M. C.; LEREBOURS, E. C.; LIN, W. J.; HARLANDER, S. K.; BERRADA, N. M.; ANTOINE, J. M.; SAVAIANO, D. A. Strains and species of lactic acid bacteria in fermented milks (yogurts): effect on in vivo lactose digestion. American Journal of Clinical Nutrition, Bethesda, v. 54, n. 12, p. 1041-1046, 1991.

MATARESE, L.E. The role of probiotic in Gastrointestinal Disease. Nutrition in Clinical Practice, Silver Spring, v. 18, n. 6, p. 507-516, 2003.

MATSUMOTO, S.; HARA, T.; HORI, T.; MITSUYAMA, K.; NAGAOKA, M.; TOMIYASU, N.; SUZUKI, A.; SATA, M. Probiotic Lactobacillus-induced improvement in murine chronic inflammatory bowel disease is associated with the down-regulation of pro-inflammatory cytokines in lamina propria mononuclear cells. Clinical and Experimental Immunology, Oxford, v. 140, n. 3, p. 417-426, 2005.

MATTO, J.; MAUNUKSELA, L.; KAJANDER, K.; PALVA, A.; KORPELA, R.; KASSINEM, S.; SAARELA, M. Composition and temporal stability of gastrointestinal microbiota in irritable bowel syndrome: a longitudinal study in IBS and control subject. FEMS Immunology and Medical Microbiology, Amsterdam, v. 43, n. 2, p. 213222, 2005.

MEULEN, R. V. D.; MAKRAS, L.; VERBRUGGHE, K.; ADRIANY, T.; VUYST, L. D. In vitro kinetic analysis of oligofructose consumption by Bacteróides and Bifidobacterium spp. indicates different degradation mechanisms. Applied and Environmental Microbiology, Washington, v. 72, n. 2, p. 1006-1012, 2006.

MEYDANI, S. N.; HA, W. Immunologic effects of yogurt. American Journal of Clinical Nutrition, Bethesda, v. 71, n. 4 , p. $861-872,2000$.

MICHETTI, P.; DORTA, G.;WIESEL, P.H.;BRASSART, D.; VERDU, E.; HERRANZ, M.; FELLEY, C.; PORTA, N.; ROUVET, M.; BLUM, A. L.; CORTHÉSYTHEULAZ, I. Effect of whey based culture supernatant of Lactobacillus acidophilus La1 on Helicobacter pylori infection in human. Digestion, Basel, v. 60, n. 3, p. 203209, 1999.

MIMURA, T.; RIZZELLO, F.; HELWIG, U.; POGGIOLI, G.; SCHREIBER, S.; TALBOT, I. C.; NICHOLLS, R. J.; GIONCHETTI, P.; CAMPIERI, M.; KAMM, M. A. Once daily high dose probiotic therapy (VSL\#3) for maintaining remission in recurrent or refractory pouchitis. Gut, London, v. 53, n. 1, p. 108-114, 2004.

MONTES, R. G.; BAYLESS, M.; SAAVEDRA, J. M.; PERMAN, J. A. Effect of milks inoculated with Lactobacillus acidophilus or a yogurt starter culture in lactose-maldigesting children. Journal of Dairy Science, Champaign, v. 78, n. 8, p. 1657-1664, 1995.

MUSTAPHA, A.; JIANG, T.; SAVAIANO, D. A. Improvement of lactose digestion by humans following ingestion of unfermented acidophilus milk: influence of bile sensitivity, lactose transport, and acid tolerance of Lactobacillus acidophilus. Journal of Dairy Science, Champaign, v. 80, n. 8, p. 1537-1545, 1997.

NAABER, P.; SMIDT, I.; STSEPETOVA, J.; BRILENE, T.; ANNUK, H.; MIKELSAAR, M. Inhibition of Clostridium difficile strains by intestinal Lactobacillus species. Journal of Medical Microbiology, Edinburgh, v. 53, n. 6, p. 551-554, 2004. 
NAIDU, A. S.; BIDLACK, W. R.; CLEMENS, R. A. Probiotic spectra of lactic acid bacteria. Critical Reviews in Food Science and Nutrition, Boca Raton, v. 38, n. 1, p. 13-126, 1999.

NICOLAS, P.; BESSIÈRES, P.; EHRLICH, S. D.; MAGUIN, E.; GUCHTE, M. V. Extensive horizontal transfer of core genome genes between two Lactobacillus species found in the gastrointestinal tract. BioMed Central Evolutionary Biology, London, v. 7, n. 141, p. 1-14, 2007.

NICOLE, J.; VIEIRA, L. Probiótico, prebiótico e simbiótico, ecossistema digestivo. Ciência Hoje, Rio de Janeiro, v. 28, n. 163, p. 34-38, 2000.

NOBAEK, S.; JOHANSSON, M. L.; MOLIN, G.; AHRNÉ, S.; JEPPSSON, B. Alteration of intestinal microflora is associated with reduction in abdominal bloating and pain in patients with Irritable Bowel Syndrome. American Journal of Gastroenterology, New York, v. 95, n. 5, p. 1231-1238, 2000.

OSMAN, N.; ADAWI, D.; MOLIN, G.; AHRNE, S.; BERGGREN, A.; JEPPSSON, B. Bifidobacterium infantis strains with and without a combination of Oligofructose and Inulin (OFI) attenuate inflammation in DSS-induced colitis in rats. Gastroenterology, Philadelphia, v. 6, n. 31, p. 1-10, 2006.

OUWERHAND, A. C.; KIRJAVAINEN P. V.; SHORTT C.; SALMINEN S. Probiotics: mechanisms and established effects. International Dairy Journal, Amsterdam, v. 9, n. 1, p. 43-52, 1999.

PANT,N.;MARCOTTE,H.;BRÜSSOW,H.;SVENSSON, L.; HAMMARSTRÖM, L. Effective prophylaxis against rotavirus diarrhea using a combination of Lactobacillus rhamnosus GG and antibodies. Microbiology, Edinburgh, v. 7, n. 86, p. 1-9, 2007.

PEDROSA, M. C.; GOLNER, B. B.; GOLDIN, B. R.; BARAKAT, S.; DALLAL, G. E.; RUSSEL, R. M. Survival of yogurt-containing organisms and Lactobacillus gasseri $(\mathrm{ADH})$ and their effect on bacterial enzyme activity in the gastrointestinal tract of healthy and hypocholorhydric elderly subjects. American Journal of Clinical Nutrition, Bethesda, v. 61, n. 2, p. 353-359, 1995.

PELUSO, I.; FINA, D.; CARUSO, R.; STOLFI, C.; CAPRIOLI, F.; FANTINI, M. C.; CASPANI, G.; GROSSI, E.; DI IORIO, L.; PAONE, F. M.; PALLONE, F.; MONTELEONE, G. Lactobacillus paracasei subsp. paracasei $\mathrm{B} 21060$ suppresses human T-cell proliferation. Infection and immunity, Washington, v. 75, n. 4, p. 17301737, 2007.

PERDIGON, G.; VINTINI, E.; ALVAREZ, S.; MEDINA, M.; MEDICI, M. Study of the possible mechanisms involved in the mucosal immune system activation by lactic acid bacteria. Journal of Dairy Science, Champaign, v.82, n. 6, p.1108-1114, 1999.

PEREIRA, D. I. A.; McCARTNEY, A. L.; GIBSON, G. R. An in vitro study of the probiotic potential of a bile-salt-hydrolyzing Lactobacillus fermentum strain, and determination of its cholesterol-lowering properties. Applied and Environmental Microbiology, Washington, v. 69, n. 8, p. 4743-4752, 2003.

PEREZ, P. F.; DORÉ, J.; LECLERC, M.; LEVENEZ, F.; BENYACOUB, J.; SERRANT, P.; SEGURAROGGERO, I.; SCHIFFRIN, E. J.; DONNET-HUGHES, A. Bacterial imprinting of the neonatal immune system: lessons from maternal cells? Pediatrics, Evanston, v. 119, n. 3, p. 724-732, 2007.

PROTIC, M.; JOJEC, N.; BOJEC, D.; MILUTINOVCS S.; NEAC D.; BOJEC B.; SVORCON P.; KRSTIC M.; POPOVIC O. Mechanism of diarrhea in microscopic colitis. World Journal of Gastroenterology, Beijing, v. 11, n. 35, p. 5535-5539, 2005.

QAMAR, A.; ABOUDOLA, S.; WARNY, M.; MICHETTI, P.; POTHOULAKIS, C.; LAMONT, J. T.; KELLY, C. N. P. Saccharomyces boulardii stimulates intestinal immunoglobulin a immune response to Clostridium difficile toxin a in mice. Infection and Immunity, Washington, v. 69, n. 4, p. 2762-2765, 2001.

RAFTER, J. Probiotics and colon cancer. Best practice and research. Journal of Clinical Gastroenterology, New York, v. 17, n. 5, p. 849-859, 2003.

RANI, B.; KHETARPAUL, N. Probiotic fermented food mixtures: possible applications in clinical anti-diarrhea usage. Nutrition and Health, Berkhamsted, v. 12, n. 2, p. 97-105, 1998.

REDDY, B. S.; RIVERSON, A. Inhibitory effect of Bifidobacterium longum on colon, mammary, and liver carcinogenesis induced by 2-amino-3methylimidazol[4,5-f]quinoline, a food mutagen. Cancer Research, Baltimore, v. 53, n. 7, p. 3914-3918, 1993.

REID, G.; HAMMOND, J. Probiotics: some evidence of their effectiveness. Canadian Family Physicians, Mississauga, v. 51, p. 1487-1493, 2005.

REID, G.; ZALAI, C.; GARDINER, G. Urogenital lactobacilli probiotics, reliability, and regulatory issues. Journal of Dairy Science, Champaign, v. 84, n. 6, p. 164169, 2001.

RESTA-LENERT, S.; BARRETT, K. Live probiotcs protect intestinal epithelial cells from the effects of infection with enteroinvasive Escherichia coli (EIEC). Gut, London, v. 52, n. 7, p. 988-997, 2003. 
RINNE, M.; KALLIOMAKI, M.; ARVILOMMI, H.; SALMINEN, S.; ISOLAURI, E. Effect of probiotics and breastfeeding on the bifidobacterium and lactobacillus/ enterococcus microbiota and humoral immune responses. Journal of Pediatrics, Saint Louis, v. 147, n. 2, p. 186191, 2005.

RODRIGUES, A. C.; NARDI R. M.; BAMBINA E. A.; VIEIRA E. C.; NICOLI J. R. Effect of Saccharomyces boulardii against experimental oral infection with Salmonella typhimurium and Shigella flexneri in conventional and gnotobiotic mice. Journal of Applied Bacteriology, Oxford, v. 81, n. 3, p. 251-256, 1996.

RODRIGUEZ, J. M. Antimicrobial spectrum, structure, properties and mode of action of nisin, a bacteriocin produced by Lactococcus lactis. Food Science and Technology International, New York, v. 2, n. 2, p. 61-68, 1996.

ROLFE, R. D. The role of probiotic cultures in the control of gastrointestinal health. Journal of Nutrition, Bethesda, v. 130, n. 2, p. 396-402, 2000.

SAARELA, M.; MOGENSEN, G.; FONDÉN, R.; MÄTTÖ, J.; MATTILA-SANDHOLM, T. Probiotic bacteria: safety, functional and technological properties. Journal of Biotechnology, Amsterdam, v. 84, n. 3, p. 197 215, 2000.

SALMINEN, S.; NURMI, J.; GUEIMONDE, M. The genomics of probiotic intestinal microorganisms. Genome Biology, London, v. 6, n. 7, p. 1-4, 2005.

SALMINEN, S.; OUWEHAND, A. C.; ISOLAURI, E. Clinical applications of probiotic bacteria. International Dairy Journal, Amsterdam, v. 8, n. 5, p. 563-572, 1998.

SARTOR, R. B. Probiotic therapy of gastrointestinal inflammation and infection. Current Opinion in Gastroenterology, Philadelphia, v. 21, n. 1, p. 44-50, 2005.

SAULNIER, D. M.A.; MOLENAAR, D.; VOS, W. M. D.; GIBSON, G. R.; KOLIDA, S. Identification of prebiotic fructooligosaccharide metabolism in Lactobacillus plantarum WCFS1 through microarrays. Applied and Environmental Microbiology, Washington, v. 73, n. 6, p. 1753-1765, 2007.

SAVAIANO, D. A.; ABOUELANOUAR, A.; SMITH, D. E.; LEVITT, M. D. Lactose malabsorption from yogurt, pasteurized yogurt, sweet acidophilus milk, and cultured milkin lactase-deficient individuals. American Journal of Clinical Nutrition, Bethesda, v. 40, n. 6, p. 1219-1223, 1984.

SAWAMURA, A.; YAMAGUCHI, Y.; TOGE, T. Enhancement of immuno-activities by oral administration of Lactobacillus casei in colorectal cancer patients. Biotherapy, Dordrecht, v. 8, p. 1567-1572, 1994.

SCANLAN, P. D.; SHANAHAN, F.; O'MAHONY, C.; MARCHESI, J. R. Culture-independent analyses of temporal variation of the dominant fecal microbiota and targeted bacterial subgroups in Crohn's disease. Journal of Clinical Microbiology, Washington, v. 44, n. 11, p. 3980-3988, 2006.

SCHIFFRIN, E. J.; ROCHAT, F.; LINK-AMSTER, H.; AESCHLIMANNP, J. M.; DONNET-HUGHES, A. lmmunomodulation of Human Blood Cells Following the Ingestion of Lactic Acid Bacteria. Journal of Dairy Science, Champaign, v. 78, n. 3, p. 491-497, 1995.

SCHLEE, M.; WEHKAMP, J.; ALTENHOEFER, A.; OELSCHLAEGER, T. A.; STANGE, E. F.; FELLERMANN, K. Induction of human defensin 2 by the probiotic Escherichia coli Nissle 1917 is mediated through flagellin. Infection and Immunity, Washington, v. 75, n. 5, p. 2399-2407, 2007.

SCHREZENMEIR, J.; DE VRESE, M. Probiotics, prebiotics and symbiotics: approaching a definition. American Journal of Clinical Nutrition, Bethesda, v. 73, n. 2, p. 361-364, 2001.

SCHULTZ, M.; STRAUCH, U. G.; LINDE, H.; WATZL, S.; OBERMEIER, F.; GÖTTL, C.; DUNGER, N.; GRUNWALD, N.; SCHÖLMERICH, J.; RATH, H. C. Preventive effects of Escherichia coli strain Nissle 1917 on acute and chronic intestinal inflammation in two different murine models of colitis. Clinical and Diagnostic Laboratory Immunology, Washington, v. 11, n. 2, p. 372-378, 2004.

SHAH, N. P. Effectiveness of dairy products in alleviation of lactose intolerance. Food Australia, Alexandria, v. 45 , n. 6, p. 268-271, 1993.

SHAH, N. P. Probiotic bacteria: selective enumeration and survival in dairy foods. Journal of Dairy Science, Champaign, v. 83, n. 4, p. 894-907, 2005.

SHAMIR, R.; MAKHOUL, I. R.; ETZIONI, A.; SHEHADEH, N. Evaluation of a diet containing probiotics and zinc for the treatment of mild diarrheal illness in children younger than one year of age. Journal of the American College of Nutrition, New York, v. 24, n. 5, p. 370-375, 2005.

SHEIL, B.; MACSHARRY, J.; O'CALLAGHAN, L.; O'RIORDAN, A.; WATERS, A.; MORGAN, J.; COLLINS, J. K.; O’MAHONY, L.; SHANAHAN, F. Role of interleukin (IL-10) in probiotic-mediated immune modulation: an assessment in wild-type and IL-10 knock-out mice. Clinical and Experimental Immunology, Oxford, v. 144, n. 2, p. 273-280, 2006. 
SHEU, B.; CHENG, H.; KAO, A.; WANG, S.; YAND, Y.; YANG, H.; WU, J. Pretreatment with Lactobacillus and Bifidobacterium containing yogurt can improve the efficacy of quadruple therapy in eradicating residual Helicobacter pylori infection after failed triple therapy. American Journal of Clinical Nutrition, Bethesda, v. 83, n. 4, p. 864-869, 2006.

SHOAF, K.; MULVEY, G. L.; ARMSTRONG, G. D.; HUTKINS, R. W. Prebiotic galactooligosaccharides reduce adherence of enteropathogenic Escherichia coli to tissue culture cells. Infection and Immunity, Washington, v. 74, n. 12, p. 6920-6928, 2006.

SNELLING, A. M. Effects of probiotics on the gastrointestinal tract. Current Opinions in Infectious Diseases, Philadelphia, v. 18, n. 5, p. 420-426, 2005.

SOZZI, T.; SMILEY, M. B. Antibiotic resistences of yogurt starter cultures Streptococcus thermophilus and Lactobacillus bulgaricus. Applied and Environmental Microbiology, Washington, v. 40, n. 5, p. 862-865, 1980.

SUGAWARA, G.; NAGINO, M.; NISHIO, H.; EBATA, T.; TAKAGI, K.; ASAHARA, T.; NOMOTO, K.; NIMURA, Y. Preoperative symbiotic treatment to prevent postoperative infectious complications in biliary cancer surgery: a randomized controlled trial. Annals of Surgery, Philadelphia, v. 244, n. 5, p. 706-714, 2006.

SZAJEWSKA, H.; MRUKOWICZ, J. Meta-analysis: non-pathogenic yeast Saccharomyces boulardi in the prevention of antibiotic-associated diarrhea. Alimentary Pharmacology and Therapeutics, Oxford, v. 22, n. 5, p. 365-372, 2005.

TAMINE, A. Y.; MARSHALL, U. M.; ROBINSON, R. $\mathrm{K}$. Microbiological and technological aspects of milk fermented by Bifodobacteria. Journal of Dairy Research, London, v. 62, n. 1, p. 151-187, 1995.

TERMONT, S.; VANDENBROUCKE, K.; ISERENTANT, D.; NEIRYNCK, S.; STEIDLER, L.; REMAUT, E.; ROTTIERS, P. Intracellular accumulation of trehalose protects Lactococcus lactis from freezedrying damage and bile toxicity and increases gastric acid resistance. Applied and Environmental Microbiology, Washington, v. 72, n. 12, p. 7694-7700, 2006.

TESHIMA, E. Aspectos terapêuticos de probióticos, prebióticos e simbióticos. In: FERREIRA, C. L. L. F. (Org.). Prebióticos e probióticos: atualização e prospecção. Viçosa-MG: Universidade Federal de Viçosa, 2003. v. 1, p. 35-60.

TOMÁS, M. S. J.; OCAÑA, V. S.; WIESE, B.; NADERMACÍAS, M. E. Growth and lactic acid production by vaginal Lactobacillus acidophilus CRL 1259, and inhibition of uropathogenic Escherichia coli. Journal of
Medical Microbiology, Edinburgh, v. 52, n. 12, p. $1117-$ 1124, 2003.

UKENA, S. N.; SINGH, A.; DRINGENBERG，U.; ENGELHARDT, R.; SEIDLER, U.; HANSEN, W.; BLEICH, A.; BRUDER, D.; FRANZKE, A.; ROGLER, G.; SUERBAUM, S.; BUER, J.; GUNZER, F.; WESTENDORF, A. M. Probiotic Escherichia coli Nissle 1917 inhibits leaky gut by enhancing mucosal integrity. Public Library of Science ONE, Cambridge, v. 2, n. 12, p. 1-9, 2007.

UKENA, S. N.; WESTENDORF, A. M.; HANSEN, W.; ROHDE, M.; GEFFERS, R.; COLDEWEY, S.; SUERBAUM, S.; BUER, J.; GUNZER, F. The host response to the probiotic Escherichia coli strain Nissle 1917: specific up-regulation of the proinflammatory chemokine MCP-1. BioMed Central Medical Genetics, London, v. 6, n. 43, p. 1-13, 2005.

VAARALA, O. Immunological effects of probiotics with special reference to lactobacilli. Clinical and Experimental Allergy, Oxford, v. 33, n. 12, p. 1634-1640, 2003.

VÉLEZ, M. P.; VERHOEVEN, T. L. A.; DRAING, C.; AULOCK, S. V.; PFITZENMAIER, M.; GEYER, A.; LAMBRICHTS, I.; GRANGETTE, C.; POT, B.; VANDERLEYDEN, J.; KEERSMAECKER, S. C. J. Functional analysis of D-alanylation of lipoteichoic acid in the probiotic strain Lactobacillus rhamnosus GG. Applied and Environmental Microbiology, Washington, v. 73, n. 11, p. 3595-3604, 2007.

VILLANI, F.; PEPE O.; MAURIELLA, G.; SALZANO, G.; MOSCHETTI, G.; COPPALA, S. Antilisterial activity of thermophilin 347 , a bacteriocin produced by Streptococcus thermophilus. International Journal of Food Microbiology, Amsterdam, v. 25, n. 2, p. 179-190, 1995.

VINDEROLA, G.; MATAR, C.; PERDIGÓN, G. Milk fermentation products of $L$. helveticus R389 activate calcineurin as a signal to promote gut mucosal immunity. BioMed Central Immunology, London, v. 8, n. 19, p. 1-10, 2007.

VITAli, B.; PUGLIESE, C.; BIAGI, E.; CANDELA, M.; TURRONI, S.; BELLEN, G.; DONDERS, G. G. G.; BRIGIDI, P. Dynamics of vaginal bacterial communities in women developing bacterial vaginosis, candidiasis, or no infection, analyzed by PCR-denaturing gradient gel electrophoresis and real-time PCR. Applied and Environmental Microbiology, Washington, v. 73, n. 18, p. 5731-5741, 2007.

WANG, K.; LI, S.; LIU, C.; PERNG, D.; SU, Y.; WU, D.; JAN, C.; LAI, C.; WANG, T.; WANG, W. Effects of 
ingesting Lactobacillus- and Bifidobacterium-containing yogurt in subjects with colonized Helicobacter pylori. American Journal of Clinical Nutrition, Bethesda, v. 80, n. 3, p. 737-741, 2004.

WARD, R. E.; NINÕNUEVO, M.; MILLS, D. A.; LEBRILLA, C. B.; GERMAN, J. B. In vitro fermentation of breast milk oligosaccharides by Bifidobacterium infantis and Lactobacillus gasseri. Applied And Environmental Microbiology, Washington, v. 72, n. 6, p. 4497-4499, 2006.

WOLLOWSKI, I.; JI, S.; BAKALINSKY, A. T.; NEUDECKER, C.; POOL-ZOBEL, B. L. Bacteria used for the production of yogurt inactivate carcinogens and prevent DNA damage in the colon of rats. Journal of Nutrition, Bethesda, v. 129, n. 1, p. 77-82, 1999.
YUKI, N.; WATANABE, K.; MIKE, A.; TAGAMI, Y.; TANAKA, R.; OHWAKI, M.; MOROTOMI, M. Survival of a probiotic, Lactobacillus casei strain Shirota in the gastrointestinal tract: selective isolation from faeces and identification using monoclonal antibiotics. International Journal of Food Microbiology, Amsterdam, v. 48, n. 1, p. 51-57, 1999.

ZÁRATE, G.; SANTOS, V.; NADER-MACIAS, M. E. Protective effect of vaginal Lactobacillus paracasei CRL 1289 against urogenital infection produced by Staphylococcus aureus in a mouse animal model. Infectious Diseases in Obstetrics and Gynecology, New York, v. 2007, n. 48358, p. 1-6, 2007.

ZHAO, J. R.; YANG, H. Progress in the effect of probiotics on cholesterol and it mechanism. Acta Microbiologica Sinica, Taiwan, v. 45, n. 2, p. 315-319, 2005. 